\title{
Assessment of microproject-based teaching/learning (MicroPBL) experience in industrial engineering degrees
}

\author{
Pernía-Espinoza, Alpha ${ }^{\text {a }}$; Sodupe-Ortega, Enrique a ; Martinez-de-Pison-Ascacibar, \\ Fco. Javier ${ }^{\text {a }}$; Urraca-Valle, Ruben ${ }^{\text {a }}$; Antoñanzas-Torres, Javier ${ }^{\text {a }}$ and Sanz-García, \\ Andres ${ }^{b}$ \\ ${ }^{a}$ EDMANS Research Group, Department of Mechanical Engineering, University of La \\ Rioja, Spain. ${ }^{\mathrm{b}}$ Faculty of Pharmacy, Centre of Drug Research (CDR), University of \\ Helsinki, Finland.
}

\begin{abstract}
An assessment program to evaluate microproject-based teaching/learning (MicroPBL) methodology on the technical subject Manufacturing Technology was implemented for four consecutive academic years. Students from three engineering degrees were involved providing feedback through various surveys that allowed us to perform a proper evaluation. More specifically, students' surveys were anonymous after each academic year, except the last one, which included both non-anonymous pre and postsurveys. The polls were mainly meant to evaluate the acquisition of specific competences (using technical questions about the subject) as well as generic ones (using questions concerning soft-skills). Students' satisfaction with the methodology and with the signature, in general, were also checked. Nonanonymous surveys enabled us to study the correlation between polls results and students' final scores. Note that students' self-assessment concerning their knowledge about technical aspects drastically changed after the course. The average final score of this subject from student's perception was slightly higher than the real value. Moreover, student's self-perception on soft-skills increased at the end of the course. In general, the proposed MicroPBL methodology demonstrated a beneficial impact on students of Manufacturing Technology keeping high-motivation levels in students as well as high success rates and scores.
\end{abstract}

Keywords: PBL; microproject; assessment; engineering degrees; competences. 


\section{Introduction}

Over the last decades, higher education institutions has broadly applied project based learning (PBL) in order to leave aside the traditional 'spoon-feeding' teaching, promoting student's active work through realistic and challenging projects (Gary, 2015). Literature reported many PBL-based activities but only few of those implemented were conducted together with proper evaluation systems. The majority used the classical 'student satisfaction survey' without going deeper in the different factors affecting students along the teaching activity (Grahm, 2010). This work presents an assessment methodology that evaluates PBL, specifically one typology called microproject-based learning methodology (MicroPBL). Authors presented the MicroPBL in previous works (Fernández-Ceniceros et al., 2015; Fernandez-Ceniceros et al., 2014) with interesting preliminary results reported (Fernández-Ceniceros et al., 2016). Briefly, MicroPBL proposes the use of small projects involving emerging manufacturing technologies on behalf of international entities acting as virtual employers. Basically, students working in teams during three weeks design, simulate and finally produce a real part that fulfills the requirements expressed by the foreign entity. Coaching, seminars given by experts, evaluation sheets are also complementary actions in the methodology. The MicroPBL was implemented in the technical signature Manufacturing Technology along four consecutive academic courses. Three engineering degrees at the University of La Rioja ('Mechanical', 'Electrical' and 'Industrial Electronic and Automation') offer this subject. During the four years, surveys provided to the students during the course together with students' final scores represent valuable information to evaluate the suitability of the methodology proposed. Last academic course (2016-2017) a complete assessment program was introduced to increase the quantity of feedback from the students. Pre and post-surveys, following the recommendation reported by (Carmenado et al., 2012; Rodriguez et al., 2015), were conducted to evaluate the influence of the MicroPBL on specific and generic competences. Importantly, as far as the surveys remained non-anonymous, they could be correlated with the student's final scores. This fact is a differentiation point with previous PBL assessment methodologies.

\section{Methodology}

Along the first three academic years, students' global perception on the MicroPBL methodology was evaluated by anonymous surveys based on a scale ranged from 1 to 4 (1 represents 'totally disagree' and 4 'totally agree'). The surveys included questions about: (i) the use of English language to define aims and tasks of the microproject and the communication with the petitioners, (ii) student's interest on MicroPBL methodology compared to traditional teaching, (iii) relevance of manufacturing tangible products and (iv) seminars given by experts or visits to local factories. 
The modified evaluation of the MicroPBL methodology for the last academic course included a complete set of surveys. Additionally to the previous evaluation, the new surveys included non-anonymous, but confidential, pre and post-surveys at the beginning and at the end of the course. The pre-survey follows the methodology proposed by (Rodriguez et al., 2015) containing questions regarding: (i) self-assessment on previous knowledge on the subject (technical questions on specific competences), (ii) selfassessment on soft-skills (questions on generic competences) and (iii) opinion and experiences regarding PBL and active learning in general. The post-survey included the previous three questions plus: (iv) evaluation of the MicroPBL methodology and (v) perception about the subject in general. The post-survey was conducted before students' grades were public.

\section{Results and Discussion}

\subsection{Anonymous surveys results at the end of each academic year}

The evolution of the results obtained from the anonymous surveys at the end of each course corresponds to the Figure 1. Authors evaluated the MicroPBL with the average scores obtained in four key areas over four consecutive academic years: 2013-2014 (104 students), 2014-2015 (82 students), 2015-2016 (72 students) and 2016-2017 (67 students). The lack of two of the four bars for the course 2013-2014 was due to the fact that the manufacturing of a tangible product and the seminars/visits were improvements implemented during the academic year 2014-2015.

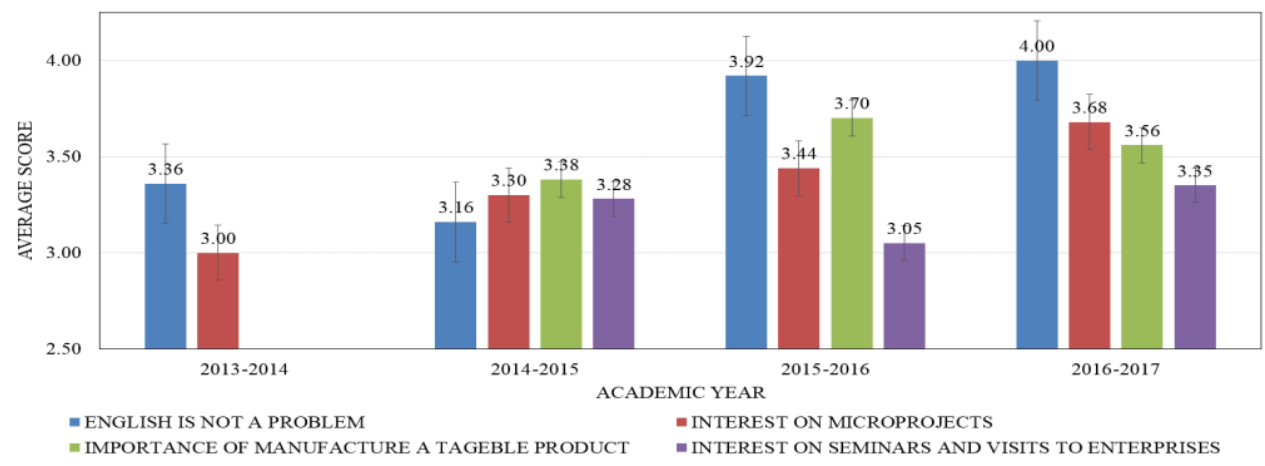

Figure 1. Results of the anonymous surveys at the end of each course to evaluate the MicroPBL methodology. 
The results indicate a positive evolution in the perception of the students concerning the use of English. Students feel that English does not represent a problem anymore for them. Note that the interest on microprojects has also risen steady every year, probably due to the improvements incorporated every year into the MicroPBL methodology with more practical and 'hands-on' elements to generate a tangible product at the end of the microprojects.

The success rates of students before and after the MicroPBL methodology (Figure 2) increased and remained stable during four academic years. The average final score showed the same behavior with a continuous increase every year with the new MicroPBL.

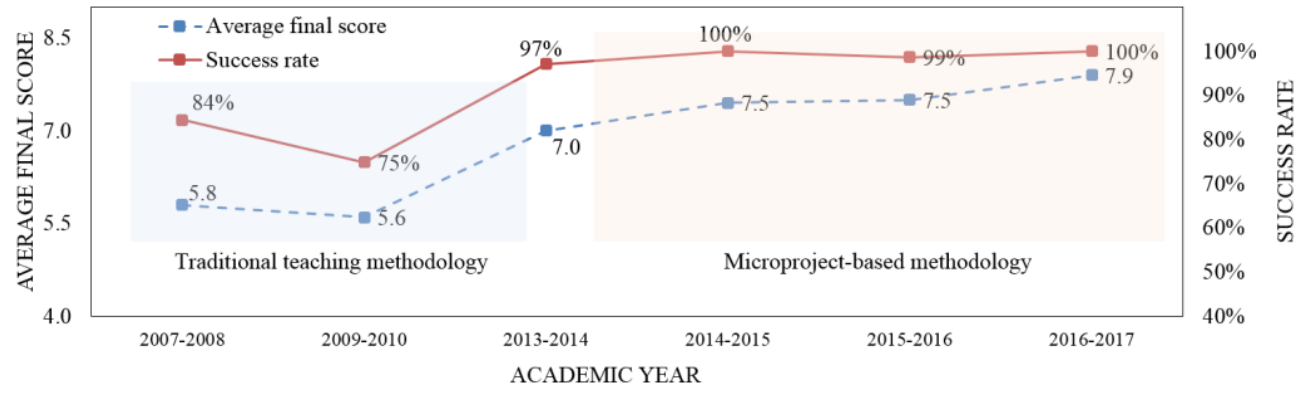

Figure 2. Average final score and success rate in the subject for academic years from 2007 to 2017

\subsection{Non-anonymous surveys results from the last academic year (2016-2017)}

A total number of 67 students were enrolled in the subject (59 male and 8 female). The surveys included 27 valid responses (paired samples). The MicroPBL methodology was applied to all the students along with other active learning methodologies, most of them based on cooperative learning.

Table 1 details average and standard error scores of students' answers to the technical questions (specific competences). Paired $t$-test was used to compare pre and post-survey results providing significant differences. Students' perception concerning their knowledge about technical aspects of the subject drastically changed after the course. Students seem to feel more confident in welding and 3D printing areas. Generally speaking, students' perception changed positively showing that they gained knowledge in technical aspect with the teaching activities and demonstrating the efficacy of MicroPBL methodology. These results are in concordance with other studies on PBL-based methods (Andersson et al., 2000; Estevez-Ayres et al., 2015; Rodriguez et al., 2015). 
Pernía-Espinoza, A.; Sodupe-Ortega, E.; Martinez-de-Pison-Ascacibar, F.J.; Urraca-Valle, R.;

Antoñanzas-Torres, J.; Sanz-García, A.

Table 1. Survey questions and pre and post-average scores regarding the subject specific competences (technical questions) (p-value $<0.05$ ).

\begin{tabular}{|c|c|c|c|c|}
\hline Question & $\begin{array}{l}\text { Pre- } \\
\text { Survey } \\
\text { Average }\end{array}$ & $\begin{array}{l}\text { Post- } \\
\text { Survey } \\
\text { Average }\end{array}$ & $\begin{array}{c}\text { t-test } \\
p \text {-value }\end{array}$ & $\begin{array}{c}\begin{array}{c}\text { Statistically } \\
\text { significant }\end{array} \\
\alpha=0.05\end{array}$ \\
\hline $\begin{array}{l}\text { Q1. I know/understand the basic principles } \\
\text { of the machining process. }\end{array}$ & $1.88 \pm 0.20$ & $3.73 \pm 0.09$ & $1.69 \mathrm{E}-08$ & YES \\
\hline $\begin{array}{l}\text { Q2. I know/understand the } \\
\text { advantages/disadvantages of the machining } \\
\text { process and when is suited to use it. }\end{array}$ & $1.73 \pm 0.16$ & $3.58 \pm 0.10$ & $5.79 \mathrm{E}-11$ & YES \\
\hline $\begin{array}{l}\text { Q3. I know/understand the basic principles } \\
\text { of the plastic injection molding. }\end{array}$ & $1.56 \pm 0.16$ & $3.42 \pm 0.11$ & $3.29 \mathrm{E}-11$ & YES \\
\hline $\begin{array}{l}\text { Q4. I know/understand the advantages/ } \\
\text { disadvantages of the plastic inyection } \\
\text { moulding and when is suited to use it. }\end{array}$ & $1.46 \pm 0.14$ & $3.27 \pm 0.13$ & $8.59 \mathrm{E}-13$ & YES \\
\hline $\begin{array}{l}\text { Q5. I know/understand the basic principles } \\
\text { of the welding process }\end{array}$ & $2.15 \pm 0.18$ & $3.85 \pm 0.07$ & $6.62 \mathrm{E}-08$ & YES \\
\hline $\begin{array}{l}\text { Q6. I know/understand the advantages/ } \\
\text { disadvantages of different welding process }\end{array}$ & $1.78 \pm 0.19$ & $3.54 \pm 0.14$ & $6.81 \mathrm{E}-10$ & YES \\
\hline $\begin{array}{l}\text { Q7. I know/understand the basic principles } \\
\text { of the metal forming process. }\end{array}$ & $1.42 \pm 0.13$ & $3.35 \pm 0.14$ & $2.28 \mathrm{E}-13$ & YES \\
\hline $\begin{array}{l}\text { Q8. I know/uderstand the } \\
\text { advantages/disadvantages of the cold and } \\
\text { hot metal forming processes. }\end{array}$ & $1.46 \pm 0.16$ & $3.54 \pm 0.10$ & $2.55 \mathrm{E}-12$ & YES \\
\hline $\begin{array}{l}\text { Q9. I am able to design/calculate an open- } \\
\text { die forging/cold rolling/ blanking/deep- } \\
\text { deep-drawing process. }\end{array}$ & $1.23 \pm 0.10$ & $3.58 \pm 0.14$ & $7.71 \mathrm{E}-16$ & YES \\
\hline $\begin{array}{l}\text { Q10. I know/understand the basic principles } \\
\text { of the 3D printing process. }\end{array}$ & $1.76 \pm 0.18$ & $3.85 \pm 0.07$ & 4.73E-10 & YES \\
\hline $\begin{array}{l}\text { Q11. I know/understand the } \\
\text { advantages/disadvantages of the } 3 \mathrm{D} \\
\text { printing process. }\end{array}$ & $1.92 \pm 0.18$ & $3.80 \pm 0.08$ & 3.69E-09 & YES \\
\hline
\end{tabular}


The non-anonymous surveys enabled us to compare students' perception about their knowledge and achievements after the subject. The average of final score from student's perception $(8.2 \pm 0.2)$ was slightly higher than the average of actual final score $(7.9 \pm 0.3)$ per student (Figure 3). A contrast $t$-test demonstrated that there was a statistically significant difference between those values. An explanation for this perception is that our methodology transmits significant feedback to the student or student's perception was overoptimistic.

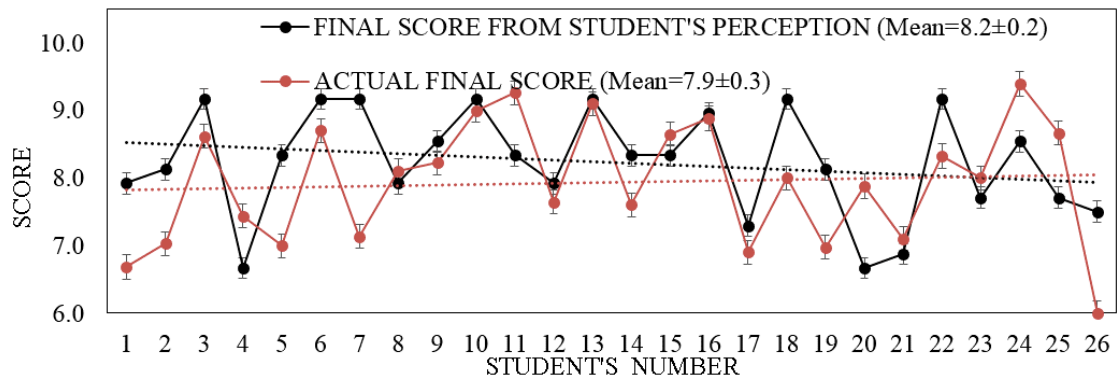

Figure 3. Comparison regarding students' final score on the subject: student's perception and actual final score.

Self-assessment results regarding generic competences (soft-skills) were divided into seven questions and represented in Table 2. Similarly to the previous survey detailed in Table 1, the score significantly increased $(\mathrm{p}<0.05)$ after the subject in all the questions formulated.

Table 2. Survey questions and pre and post-average scores regarding the subject generic competences questions (soft-skill questions).

\begin{tabular}{lcccc}
\hline \multicolumn{1}{c}{ Question } & $\begin{array}{c}\text { Pre- } \\
\text { Survey } \\
\text { Average }\end{array}$ & $\begin{array}{c}\text { Post- } \\
\text { Survey } \\
\text { Average }\end{array}$ & $\begin{array}{c}\text { t-test } \\
\boldsymbol{p} \text {-value }\end{array}$ & $\begin{array}{c}\text { Statistically } \\
\text { significant } \\
\boldsymbol{\alpha}=\mathbf{0 . 0 5}\end{array}$ \\
\hline Q1. I have great oral comm. skills & $2.92 \pm 0.09$ & $3.16 \pm 0.12$ & $1.31 \mathrm{E}-07$ & YES \\
Q2. I have excellent team working skills & $3.31 \pm 0.09$ & $3.54 \pm 0.14$ & $2.55 \mathrm{E}-03$ & YES \\
Q3. I have strong team leadership skills & $2.92 \pm 0.10$ & $3.35 \pm 0.14$ & $3.40 \mathrm{E}-06$ & YES \\
$\begin{array}{l}\text { Q4. I solve problems creatively } \\
\text { Q5. I can get what really matters from }\end{array}$ & $3.08 \pm 0.09$ & $3.32 \pm 0.11$ & $1.71 \mathrm{E}-05$ & YES \\
texts and everyday situations & & $3.42 \pm 0.13$ & $1.25 \mathrm{E}-03$ & YES \\
$\begin{array}{l}\text { Q6. I manage my time efficiently } \\
\begin{array}{l}\text { Q7. I am a proactive person that propose } \\
\text { and implement solutions }\end{array}\end{array}$ & $2.96 \pm 0.12$ & $3.38 \pm 0.14$ & $5.31 \mathrm{E}-07$ & YES \\
\hline
\end{tabular}


The scores observed in the generic competences show that students felt more confident on their soft-skills after the course. This effect might be considered as an enhancement of their self-confident on soft-skills thanks to the PBL-based methodology proposed, somehow also observed by other authors (Frank et al., 2003; Rodriguez et al., 2015). Team leadership, time management and proactivity resulted in the highest differences, being time management a target skill for improving in the following experiences.

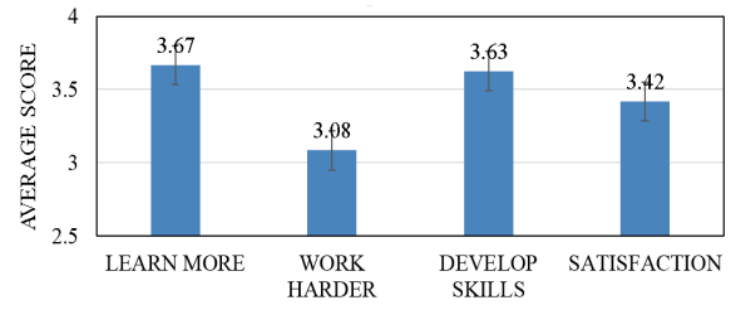

a.

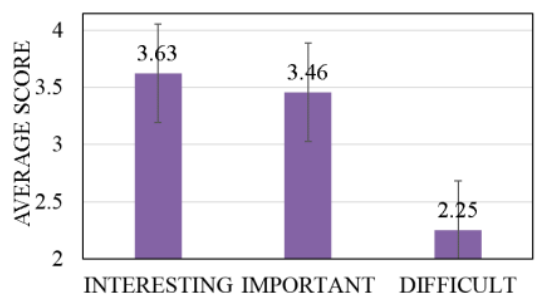

b.

Figure 4. a) Students' average scores regarding the MicroPBL methodology questions. b) Average scores of postsurvey questions regarding the signature in general.

Students considered that MicroPBL methodology allowed them to learn more, develop more soft-skills and with more satisfactory results than with the traditional learning methods (Figure 4.a). They also think that they do not work harder or the subject is less difficult to them (Figure 4.b), contrary to other PBL experiences, where students usually answered the opposite (Rodriguez et al., 2015). This is probably due to the lower complexity of the tasks proposed in this generalist and introductory subject, but this may change along advanced subjects related to their degree.

\section{Conclusions}

An assessment program to evaluate MicroPBL methodology on the technical subject 'Manufacturing Technology' was implemented for four academic years. Surveys were anonymous every year except the last one, in which non-anonymous pre and post-surveys to evaluate the acquisition of specific and generic competences were conducted. These allowed us to correlate students' perceptions and final scores. Students' self-assessment concerning their knowledge about technical aspects drastically changed after the course. The average of the subject's final score from student's perception was slightly higher than the actual value. Moreover, student's self-perception on soft-skills increased after the course. Both appreciations are in agreement with other reported experiences. Summarizing, the MicroPBL methodology demonstrated beneficial for the technical subject maintaining high-motivation students, which was directly related to students' success rates and final scores. 


\section{Acknowledgements}

The authors would like to acknowledge University of La Rioja for the financial support received through the program 'Proyectos de Innovación Docente 2016/2017', as well as for the FPI-UR fellowships (E. S., J. A. and R. U.) and EGI16/19 fellowship. The authors also want to express their gratitude to the Instituto de Estudios Riojanos (IER) and to the Banco Santander for the APPI16/05 fellowship. One of the authors, A.S.G., would also like to acknowledge the financial support from the Academy of Finland No. 273689. We would like to thank to the special collaboration of all student involved in this experience.

\section{References}

Andersson, P., Carpenter, D., Christie, M., Duque, M., Farreras, M., Graaff, E., 2000. Active Learning in Engineering Education.

Carmenado, I.d.1.R., Rodríguez, B.F., Gajardo, F.G., 2012. Methodological Proposal for Teamwork Evaluation in the Field of Project Management Training. Procedia - Social and Behavioral Sciences 46, 1664-1672.

Estevez-Ayres, I., Alario-Hoyos, C., Perez-Sanagustin, M., Pardo, A., Crespo-Garcia, R.M., Leony, D., Parada G, H.A., Delgado-Kloos, C., 2015. A methodology for improving active learning engineering courses with a large number of students and teachers through feedback gathering and iterative refinement. International Journal of Technology and Design Education 25, 387-408.

Fernández-Ceniceros, J., Sanz-García, A., Antoñanzas-Torres, F., Alía-Martínez*, M., Pernía-Espinoza, A., 2015. Microproject-based teaching/learning methodology focused on emerging technologies and international entities cooperation, In: Domenech, J., Vincent-Vela, M.C., Peña-Ortiz, R., Poza, E.d.1., Blazquez, D. (Eds.), 1st International Conference on Higher Education Advances, HEAd'15. Universitat Politecnica de València Valencia-Spain, pp. 311-318.

Fernández-Ceniceros, J., Sanz-García, A., Antoñanzas-Torres, F., Alía-Martínez*, M., Pernía-Espinoza, A., 2016. Teaching/learning methodologies based on microprojects and internationalization to increase students' motivation on technical subjects, In: València, U.P.d. (Ed.), Advances in Higher Education. Editorial Universidad Politécnica de Valencia Valencia-Spain, pp. 191-207.

Fernandez-Ceniceros, J., Sanz-Garcia, A., R., U.-V., Martinez-de-Pison-Ascacibar, F., Pernia-Espinoza, A., 2014. Modelo de Enseñanza-Aprendizaje basado en microproyectos para la asignatura Tecnología de Fabricación, CUIEET 2014. XXII Congreso Universitario de Innovación Educativa en las Enseñanzas Técnicas, Almaden, Spain.

Frank, M., Lavy, I., Elata, D., 2003. Implementing the Project-Based Learning Approach in an Academic Engineering Course. International Journal of Technology and Design Education 13, 273-288.

Grahm, R., 2010. UK Approaches to Engineering Project-Based Learning, Report form the Gordon-MIT Engineering Leadership Program at MIT. Massachusetts Institute of Technology: MIT, Massachuset, USA. 
Pernía-Espinoza, A.; Sodupe-Ortega, E.; Martinez-de-Pison-Ascacibar, F.J.; Urraca-Valle, R.; Antoñanzas-Torres, J.; Sanz-García, A.

Rodriguez, J., Laveron-Simavilla, A., del Cura, J.M., Ezquerro, J.M., Lapuerta, V., Cordero-Gracia, M., 2015. Project Based Learning experiences in the space engineering education at Technical University of Madrid. Advances in Space Research 56, 13191330. 